\title{
An Optimization Algorithm for Exponential Curve Model of Single Pile Bearing Capacity
}

\author{
Hongmei Ma $\cdot$ Cheng Peng $\cdot$ Jinying Gan $\cdot$ Yonghong Deng
}

Received: 27 May 2019/Accepted: 11 December 2020/Published online: 22 January 2021

(C) The Author(s) 2021

\begin{abstract}
The ultimate bearing capacity of single pile is very important to engineering safety, so correctly predicting its value becomes an important part of engineering safety. Based on the traditional exponential curve model, a parameter optimization algorithm of the exponential curve model of single pile bearing capacity, which combines the golden section method and the linear least square method, is proposed. In order to verify the reliability of the proposed optimization algorithm, the measured data of the building engineering in the literature were optimized and calculated. Through comparison, it is found that the optimization algorithm is closer to the measured value than the traditional exponential curve model algorithm, which can better guide the engineering practice, and verify the effectiveness and superiority of the proposed parameter optimization method.
\end{abstract}

Keywords Ultimate bearing capacity - Exponential curve model · Golden section search · Linear least squares

H. Ma $(\varangle) \cdot$ C. Peng $\cdot$ J. Gan · Y. Deng

School of Electronic and Information Engineering, North

China University of Science and Technology,

Yanjiao Town, East of Beijing 065201, China

e-mail: mhm_1975@126.com

\section{Introduction}

The bearing capacity of piles can be determined based on conventional semi-empirical equations. In this regard, the Meyerhof equation is still well-respected. In addition, there are some simple correlations between the bearing capacity of piles and in-situ tests (like cone penetration test, CPT or standard penetration test, SPT); however, some studies suggest that the aforementioned correlations overestimate the bearing capacity. Furthermore, some other studies recommend the use of dynamic equations, which are based on the pile and hammer properties, to estimate the bearing capacity of piles; however, as stated by Milad et al. (Milad et al. 2015), there are many assumption and simplification in estimating the bearing capacity using the aforementioned equations. (Ehsan Momeni et al. 2020; HAN Jiwei et al. 2020).

Reasonable and correct prediction of vertical ultimate bearing capacity of single pile is the most important safety premise in pile foundation engineering. The existing models are widely used because of the advantages of exponential curve model. In the use of exponential curve model, the reasonable solution of its unknown parameters is the key problem for prediction. The existing methods mainly use the traditional intelligent optimization algorithm or gradient optimization algorithm to complete this task (Peng et al. 2010). In engineering, we find that we can explore more optimized algorithm, so we propose an optimization algorithm combining golden section 
method and linear least square algorithm. (Julong et al. 2012; Xing et al. 2016).

\section{Problem Description}

In order to predict the ultimate bearing capacity, the exponential curve model is used in this paper (Deling 2003; Nehdi 2015).

$Q=Q_{u}\left(1-A e^{-B s}\right)$,

In it, S represents stable settlement ( $\mathrm{mm}), \mathrm{Q}$ is the test load corresponding to $\mathrm{s}(\mathrm{kN})$, Unknown parameters in the model are A,B and theoretical ultimate bearing capacity $Q_{u}(\mathrm{kN})$ at $\mathrm{s} \rightarrow \infty$

It is assumed that the stable settlement of $n$ group $S_{i}$ $(i=1,2, \ldots n)$ and its corresponding test load $Q_{i}$ $(\mathrm{i}=1,2, \ldots \mathrm{n})$ are obtained by test pile test, then the unknown parameter can be obtained by optimizing that nonlinear least squares cost function (Jiang et al. 2016).

$\min J\left(A, B, Q_{u}\right)=\sum_{i=1}^{n}\left(Q_{i}-Q_{u}\left(1-A e^{-B s_{i}}\right)\right)^{2}$

\section{Exponential Curve Fitting Method}

\subsection{Separable Least Squares Problem}

Genetic algorithm may also be used Genetic algorithms can also be used. The nonlinear least squares cost function defined by (2) can be solved by standard nonlinear least squares optimization method, such as Gauss-Newton method or Marquardt method. Genetic algorithm, differential evolution and other intelligent optimization methods can also be used to solve this problem. However (Yan et al. 2015; Zhang et al. 2015), the above methods do not take into account the characteristics of the unknown parameters in the model (1). For the convenience of analysis, order:

$A_{1}=Q_{u} \times A$,

Then the formula (1) and (2) are converted into:

$Q=Q_{u}-A_{1} e^{-B s}$, $\min J\left(A, B, Q_{u}\right)=\sum_{i=1}^{n}\left(Q_{i}-\left(Q_{u}-A_{1} e^{-B s_{i}}\right)\right)^{2}$

And then it's easy to know, If B is known quantity, The nonlinear least squares problem defined by (5) will be simplified to a linear least squares problem. In addition, if let:

$N=\left[\begin{array}{c}Q_{1} \\ Q_{2} \\ \vdots \\ Q_{n}\end{array}\right], \ldots M=\left[\begin{array}{cc}1 & e^{-B s_{1}} \\ 1 & e^{-B s_{2}} \\ \vdots & \vdots \\ 1 & e^{-B s_{n}}\end{array}\right]$

Another two unknown parameters in the formula (4):

$\left[\begin{array}{l}Q_{u} \\ A_{1}\end{array}\right]=\left(M^{T} M\right)^{-1} M^{T} N$

Through the analysis above, we can see that the nonlinear least squares problem defined by (5) is variable separable. For this kind of nonlinear least squares problem, the nonlinear parameters and linear parameters can be divided into two groups estimated separately. The nonlinear parameter B can be estimated by nonlinear optimization techniques. In this paper, golden section method as a commonly used method in univariate optimization problems is used. $Q_{u}$ and A1 are linear parameters, them can be obtained through formula (7).

\subsection{Golden Section Method}

The main idea of the golden section method is to find the optimal solution by narrowing the area of the optimal solution step by step. In the process of optimization, only the value of the finite cost function needs to be calculated. To calculate the objective function value required by the golden section method (Arnau et al. 2012), let B take a particular value, First, the linear parameters $Q_{u}$ and A1 corresponding to B is calculated by formula (7), the objective function $\mathrm{J}$ corresponding to $\mathrm{B}, Q_{u}$ and $\mathrm{A} 1$ is calculated by the formula (5).

For one dimension optimization problem:

$\min f(x), \quad x \in[a, b]$

Order constant $\theta=0.618$, the first step in the Golden Section, let $x_{1}=a+(1-\theta) \times(b-a)$, $x_{2}=a+b-x_{1}$, Calculate $f\left(x_{1}\right)$ and $f\left(x_{2}\right)$. 
The second step in the Golden Section is to compare the size of $f\left(x_{1}\right)$ and $f\left(x_{2}\right)$. If $f\left(x_{1}\right) \leq f\left(x_{2}\right)$, the interval of the optimal solution is reduced to [a, $\left.x_{2}\right]$, this situation order $b=x_{2}$, the interval of the optimal solution can still be recorded as $[\mathrm{a}, \mathrm{b}]$, at the same time, let $\quad x_{2}=x_{1}, \quad f\left(x_{2}\right)=f\left(x_{1}\right)$, $x_{1}=a+(1-\theta) \times(b-a)$, calculate the value of $f\left(x_{1}\right)$; If $f\left(x_{1}\right)=f\left(x_{2}\right)$, the interval of the optimal solution is reduced to $\left[x_{1}, b\right]$, at this point, $a=x_{1}$, the interval of the optimal solution can still be recorded as $[a, b]$, at the same time, let $x_{2}=x_{1}, f\left(x_{2}\right)=f\left(x_{1}\right)$, $x_{1}=a+\theta \times(b-a)$, then calculate $f\left(x_{2}\right)$.

The second step is repeated several times until the length of the interval $[a, b]$ is less than a predetermined constant $\varepsilon$, so that the optimal solution $x_{b}=(a+b) / 2$ can be obtained.

After each iteration, the golden section reduces the length of the search interval to $\theta$ times that of the previous one (Xue et al. 2015; Sun et al. 2015).

\subsection{Algorithm Flow}

In summary, the golden section-least square procedure of estimating the unknown parameters $\mathrm{alb}$ and qu in the exponential curve model defined by the formula (1) is as follows:

(1) Sets the constant $\varepsilon$ required to end the golden section search, order constant $\theta=0.618$; Sets the range of values of the parameter $\mathrm{B}[\alpha, \beta]$.

(2) Let $B_{1}=a+(1-\theta) \times(\beta-\alpha)$, the corresponding objective function $J_{1}$ is calculated by the formula (5); Let $B_{2}=a+\beta-B_{1}$, the corresponding objective function $J_{2}$ is calculated by the formula (5).

(3) Compare the size of $J_{1}$ and $J_{2}$. If $J_{1} \leq J_{2}$, order $\beta=B_{2}, \quad B_{2}=B_{1}, \quad J_{2}=J_{1}$, $B_{1}=a+(1-\theta) \times(\beta-\alpha), J_{1}$ is calculated by the formula (5); Otherwise, order $\alpha=B_{1}$, $B_{1}=B_{2}, J_{1}=J_{2}, B_{2}=a+\theta \times(\beta-\alpha), J_{2}$ is calculated by the formula (5).

(4) If $\beta-\alpha \geq \varepsilon$, return to the step (3); Otherwise, let the optimal solution $B^{*}=(\alpha+\beta) / 2$, the linear parameter and corresponding to $B^{*}$ are calculated by formula(3), (4), the objective function $\mathrm{J}^{*}$ corresponding to, and can be calculated by formula (5). Let $A^{*}=A^{*} 1 / Q^{*} \mathrm{u}$, to find out the optimal solution $B^{*}, A^{*}, Q^{*} \mathrm{u}$ and the optimal objective function $\mathrm{J}^{*}$.

\section{Example of Practical Calculation}

To verify the performance of the above algorithm, Taking into account the static load test data of Wuhan Power Market Building provided by reference (Deling 2003), Set the constant $\varepsilon=1 \times 10^{-4}$ required by the golden section method, Set the range of parameter $B[0,20]$ (Fig. 1).

According to the static load test data of Wuhan power market building provided by literature (Deling 2003), the predicted value is calculated by golden section least square method according to the algorithm flow of 3.3, and compared with the prediction data in literature (Deling 2003) and Literature. The detailed results are shown in Table 1.

The model fitting accuracy in Table 1 is defined as:

$\psi=\sqrt{1-\sum_{i=1}^{n}\left(Q_{i}-Q_{i}^{m}\right)^{2} / \sum_{i=1}^{n}\left(Q_{i}-\bar{Q}\right)^{2}}$

where $Q_{i}^{m}$ corresponds to $Q_{i}$, The load value calculated by the model is $\mathrm{KN}, \bar{Q}$ is the average value of measured load $Q_{i}(\mathrm{i}=1,2, \ldots \mathrm{n})$ (Fig. 2 and Table 2).

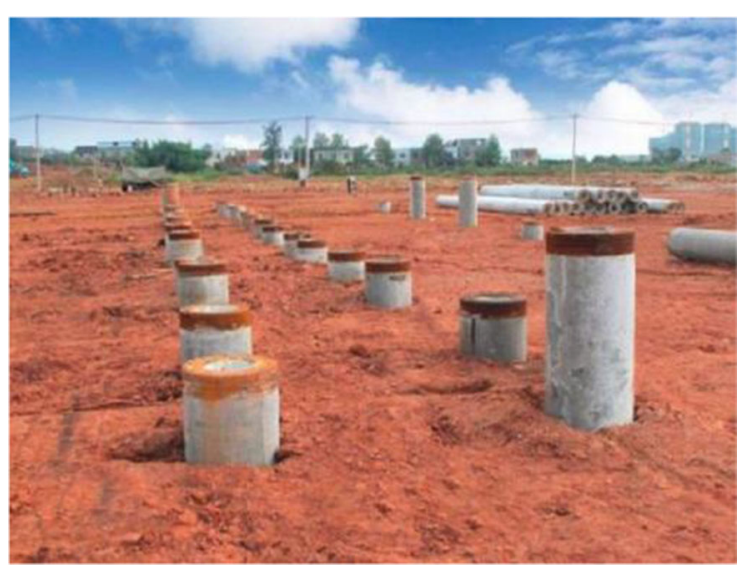

Fig. 1 The picture of single pile 
Table 1 The optimal solutions obtained by different methods and their comparison

\begin{tabular}{llll}
\hline Calculation results & $\begin{array}{l}\text { Literature (Deling } \\
2003)\end{array}$ & Literature & This paper \\
\hline$A$ & 0.9470 & 0.8600 & 0.8607 \\
$B$ & 0.0650 & 0.0552 & 0.0568 \\
$Q_{\mathrm{u}}$ & 7000 & 7151 & 7070 \\
$\psi$ & 0.9855 & 0.9932 & 0.9934 \\
$J$ & $1.34 \times 10^{6}$ & $6.24 \times 10^{5}$ & $5.96 \times 10^{5}$ \\
\hline
\end{tabular}

\section{Conclusion}

According to the traditional exponential model curve fitting method, an exponential model curve fitting optimization algorithm is proposed, and its theoretical prediction of the ultimate load of a single pile is deduced. The calculation results for typical problems show that this method has the advantages of small amount of calculation and high model accuracy. From the data, the fitting precision of curve fitting optimization algorithm of exponential model is higher than that of traditional method. Through comparison, it can be seen that the exponential model curve fitting optimization algorithm is more safe and reliable to predict the limit load value, and can meet the need of high precision in prediction or design.
Table 2 Comparison table of different algorithm fitting results

\begin{tabular}{lllll}
\hline Settle-Ments/mm & \multicolumn{2}{l}{ Load $Q / k N$} & & \\
\cline { 2 - 5 } & measured value & $\begin{array}{l}\text { Literature (Deling } \\
2003)\end{array}$ & Literature & this paper \\
\hline 0.58 & 1123 & 616 & 1195 & 1182 \\
2.20 & 1685 & 1254 & 1704 & 1699 \\
4.75 & 2246 & 2132 & 2419 & 2423 \\
7.31 & 2808 & 2878 & 3043 & 3052 \\
8.02 & 3370 & 3064 & 3201 & 3211 \\
8.51 & 3931 & 3187 & 3306 & 3317 \\
15.43 & 4493 & 4569 & 4526 & 4536 \\
20.56 & 5054 & 5258 & 5173 & 5177 \\
23.98 & 5346 & 5605 & 5513 & 5511 \\
26.33 & 5553 & 5803 & 5713 & 5706 \\
28.85 & 5824 & 5984 & 5899 & 5888 \\
31.24 & 6032 & 6130 & 6054 & 6038 \\
33.91 & 6240 & 6269 & 6204 & 6183 \\
37.35 & 6448 & 6415 & 6368 & 6340 \\
40.12 & 6556 & 6511 & 6479 & 6447 \\
\hline
\end{tabular}


Acknowledgements The project was supported by the Central University Basic Research Operating Funding Project (3142012036, 3142012039).

Open Access This article is licensed under a Creative Commons Attribution 4.0 International License, which permits use, sharing, adaptation, distribution and reproduction in any medium or format, as long as you give appropriate credit to the original author(s) and the source, provide a link to the Creative Commons licence, and indicate if changes were made. The images or other third party material in this article are included in the article's Creative Commons licence, unless indicated otherwise in a credit line to the material. If material is not included in the article's Creative Commons licence and your intended use is not permitted by statutory regulation or exceeds the permitted use, you will need to obtain permission directly from the copyright holder. To view a copy of this licence, visit http://creativecommons.org/licenses/by/4.0/.

\section{References}

Arnau O, Molins C (2012) Three dimensional structural response of segmental tunnel linings. Eng Struct 44(6):210-221

Cheng P, Yong W (2010) Frequency domain identification of vibration system stability model. Vib shock 29(3):118-120

Deling Q (2003) Interaction mechanism between soil and pile with variable section[M]. HeFei University of Technology Press, HeFei, pp 58-61

Jiang H, Cao Q, Liu A et al (2016) Flexural behavior of precast concrete segmental beams with hybrid tendons and dry joints. Constr Build Mater 110:1-7

Jiwei H, Xiaoming L, Yuehong Y et al (2020) Study on the horizontal bearing capacity of single pile foundation considering spatial variability of soil strength. Hydr Sci Eng
Julong S, Xiangke W, Xiaohui F (2012) optimization method [M]. Xian Electronic Sience \& Technology University Press, XiAn

Milad F, Kamal T, Nader H, Erman OE (2015) New method for predicting the ultimate bearing capacity of driven piles by using Flap number. KSCE J Civ Eng 19:611-620

Momeni E, Dowlatshahi MB, Omidinasab F et al (2020) Gaussian process regression technique to estimate the pile bearing capacity. Arab J Sci Eng 45:8255-8267

Nehdi ML, Abbas S, Soliman AM (2015) Exploratory study of ultra-high performance fiber reinforced concrete tunnel lining segments with varying steel fiber lengths and dosages. Eng Struct 101:733-742

Sun LH, Wu HY, Yang BS et al (2015) Support failure of a highstress soft-rock roadway in deep coal mine and the equalized yielding support technology: a case study. Int J Coal Sci Technol 2(4):279-286

Xing Wanli Yu, Yinquan JH et al (2016) Experimental study on large-span steel arch in Shijiazhuang railway station. Build Struct 19:21-25

Xue JH, Wang HP, Zhou W et al (2015) Experimental research on overlying strata movement and fracture evolution in pillarless stress-relief mining. Int $\mathbf{J}$ Coal Sci Technol 2(1):38-45

Yan ZG, Shen Y, Zhu HH et al (2015) Experimental investigation of reinforced concrete and hybrid fibre reinforced concrete shield tunnel segments subjected to elevated temperature. Fire Saf J 71(3):86-99

Zhang CH, Wang LG, Du JH et al (2015) Numerical modelling rock deformation subject to nitrogen cooling to study permeability evolution. Int J Coal Sci Technol 2(4):1-6

Publisher's Note Springer Nature remains neutral with regard to jurisdictional claims in published maps and institutional affiliations. 